\title{
Chiral cyclopentadienylruthenium sulfoxide catalysts for asymmetric redox bicycloisomerization
}

\author{
Barry M. Trost ${ }^{*}$, Michael C. Ryan and Meera Rao
}

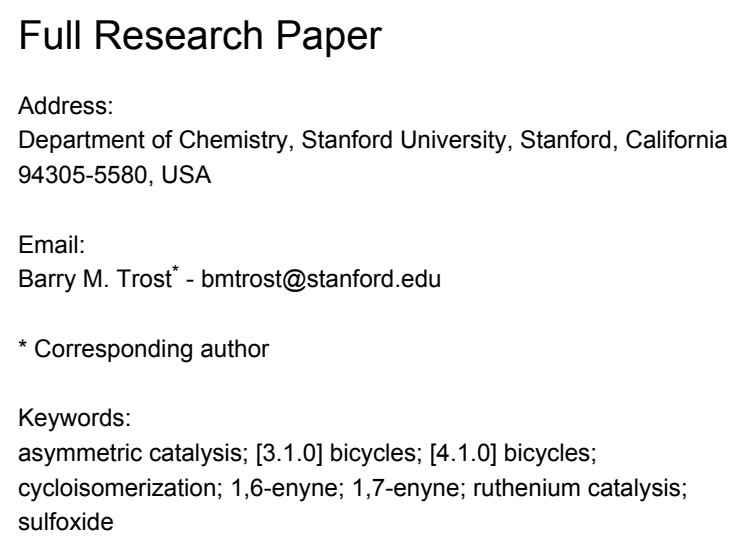

Open Access
Beilstein J. Org. Chem. 2016, 12, 1136-1152.
doi:10.3762/bjoc.12.110
Received: 16 March 2016
Accepted: 03 May 2016
Published: 07 June 2016
This article is part of the Thematic Series "Organometallic chemistry" and
is dedicated to the memory of Prof. Peter Hofmann.
Guest Editor: L. Gade
C 2016 Trost et al; licensee Beilstein-Institut.
License and terms: see end of document.

\begin{abstract}
A full account of our efforts toward an asymmetric redox bicycloisomerization reaction is presented in this article. Cyclopentadienylruthenium $(\mathrm{CpRu})$ complexes containing tethered chiral sulfoxides were synthesized via an oxidative [3 +2$]$ cycloaddition reaction between an alkyne and an allylruthenium complex. Sulfoxide complex 1 containing a $p$-anisole moiety on its sulfoxide proved to be the most efficient and selective catalyst for the asymmetric redox bicycloisomerization of 1,6- and 1,7-enynes. This complex was used to synthesize a broad array of [3.1.0] and [4.1.0] bicycles. Sulfonamide- and phosphoramidate-containing products could be deprotected under reducing conditions. Catalysis performed with enantiomerically enriched propargyl alcohols revealed a matched/mismatched effect that was strongly dependent on the nature of the solvent.
\end{abstract}

\section{Introduction}

Due to their prevalence in natural products [1], medicinal targets [2], and materials [3], organic chemists have made the construction of cyclic, organic molecules one of the most important areas of research in their discipline. Of the available methods to affect cyclization, transition metal-catalyzed enyne cycloisomerizations [4] have been recognized as an atom- [5], step- [6], and redox-economical [7] class of reactions that are able to stitch together cyclic molecules quickly and efficiently.

The very first enyne cycloisomerization reactions were reported by the Trost group while they were synthesizing sub-

strates intended for thermal Alder-ene reactions [8]. They serendipitously discovered that palladium(II) salts catalyzed the cyclization of 1,6-enynes at much lower temperatures compared to the thermal process [9], which normally requires temperatures in excess of $200{ }^{\circ} \mathrm{C}$ (Scheme 1, path a).

More recently, the same research group disclosed a $\mathrm{CpRu}(\mathrm{MeCN})_{3} \mathrm{PF}_{6}$-catalyzed variant of the same reaction that proceeds even at room temperature [10]. The ruthenium process differs from the initially-discovered palladium reaction in that it produces cyclic 1,4-dienes exclusively; no olefin isomerization 


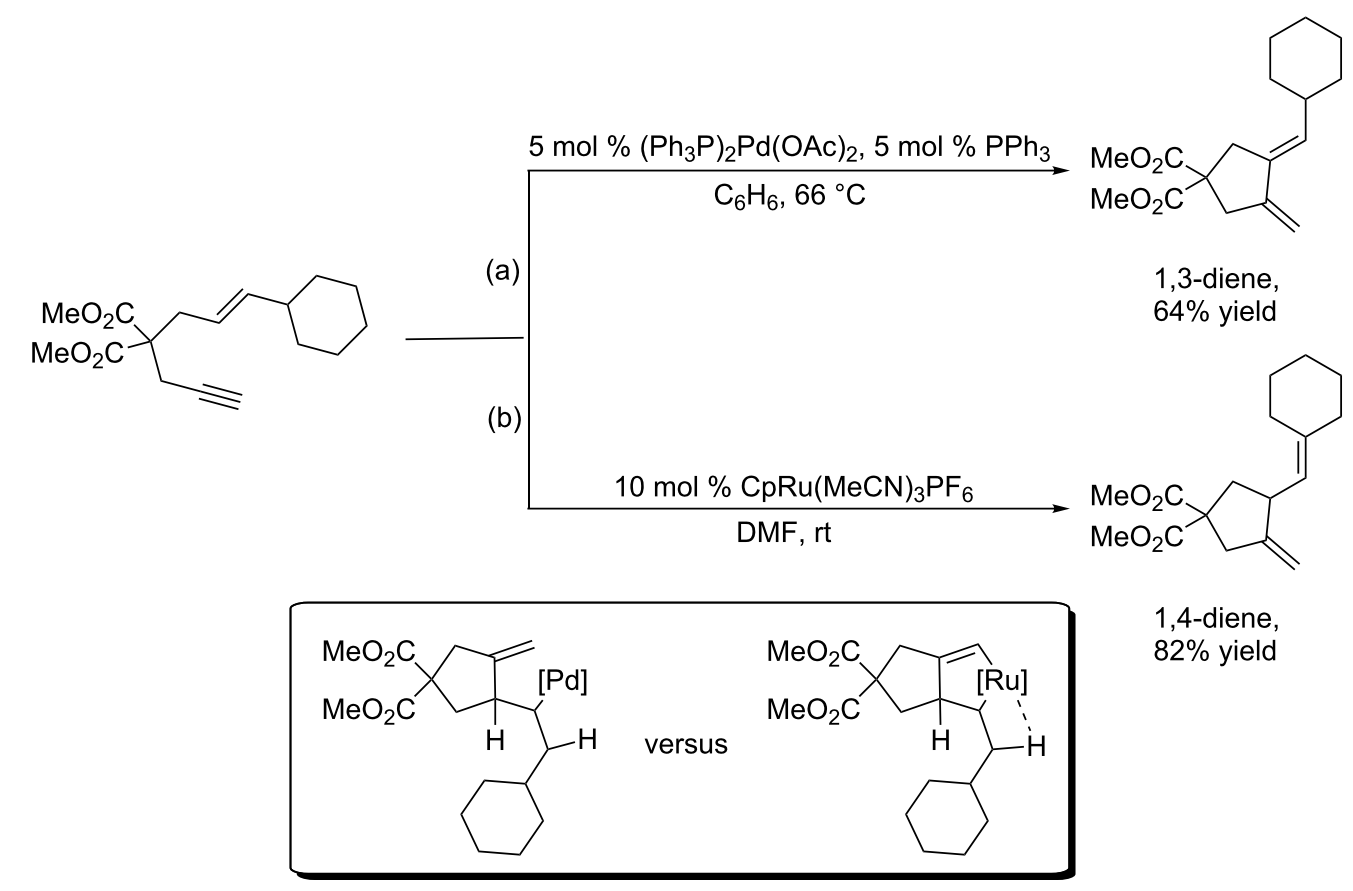

Scheme 1: Divergent behavior of the palladium and ruthenium-catalyzed Alder-ene reaction.

is detected (Scheme 1, path b). Moreover, ruthenium can tolerate many sensitive functional groups, such as free alcohols, silyl enol ethers, and ketones, which makes it an attractive metal for late stage functionalization and elaboration of complex molecules. It is thought that the origin of ruthenium's divergent behavior stems from a difference in reaction mechanism. Whereas the palladium-catalyzed Alder-ene reaction proceeds through an initial hydrometallation of a palladium hydride intermediate, ruthenium is speculated to first form a ruthenacyclopentene prior to $\beta$-hydride elimination. Since the hydrogen leading to the 1,3-diene is inaccessible to the ruthenacyclopentene, it must exclusively abstract the exocyclic hydrogen, which results in 1,4-diene formation. Palladium, which is not restricted to a metallacycle, is free to choose either hydrogen, and therefore performs $\beta$-hydride elimination on the allylic hydrogen.

Recognizing that enantioenriched, cyclic molecular architectures hold a particular interest to the chemical community, especially in the fields of natural product synthesis and drug design, researchers have made a significant effort to discover asymmetric variations of enyne cycloisomerization reactions $[11,12]$. Researchers have used a variety of transition metals to affect asymmetric enyne cycloisomerization [13-23]. In particular, Mikami has disclosed a palladium-catalyzed asymmetric enyne cycloisomerization where a tetrahydrofuran containing a quaternary, all-carbon stereocenter is created in excellent yield and selectivity [24] (Scheme 2a). Unfortunately, the scope of this reaction is rather limited, as this is the only example presented in the paper. Mechanistic studies performed by the same group on this system support a hydropalladation/cyclization/ $\beta$-hydride elimination mechanism. Rhodium catalysis of simple 1,6enynes displayed a broader scope than Mikami's palladium system, although none of the examples contained a quaternary stereocenter [25].

Asymmetric enyne cycloisomerization reactions can be extended beyond the construction of 1,4-dienes, depending on the transition metal used and the adjacent functionality on the substrate in question. For example, Hayashi has shown that a rhodium/phosphoramidite catalysis is particularly effective for asymmetric [5+2] cycloaddition reactions (Scheme $2 b$ ). The $(S, R, R)$-diastereomer of the Feringa-style phosphoramidite ligand proved to be crucial to both the yield and enantioselectivity of this reaction, as there was a severe matched/mismatched effect observed with another diastereomer. In contrast to the ruthenium-catalyzed [ $5+2$ ] cycloaddition of enynes, which is thought to proceed through a ruthenacyclopentene intermediate [26], it has been proposed that rhodium first undergoes oxidative cyclization with the vinylcyclopropane prior to alkyne insertion.

The asymmetric enyne cycloisomerization reaction has been shown to be instrumental in the construction of medicinal chemistry targets. For example, the Fürstner group realized that 


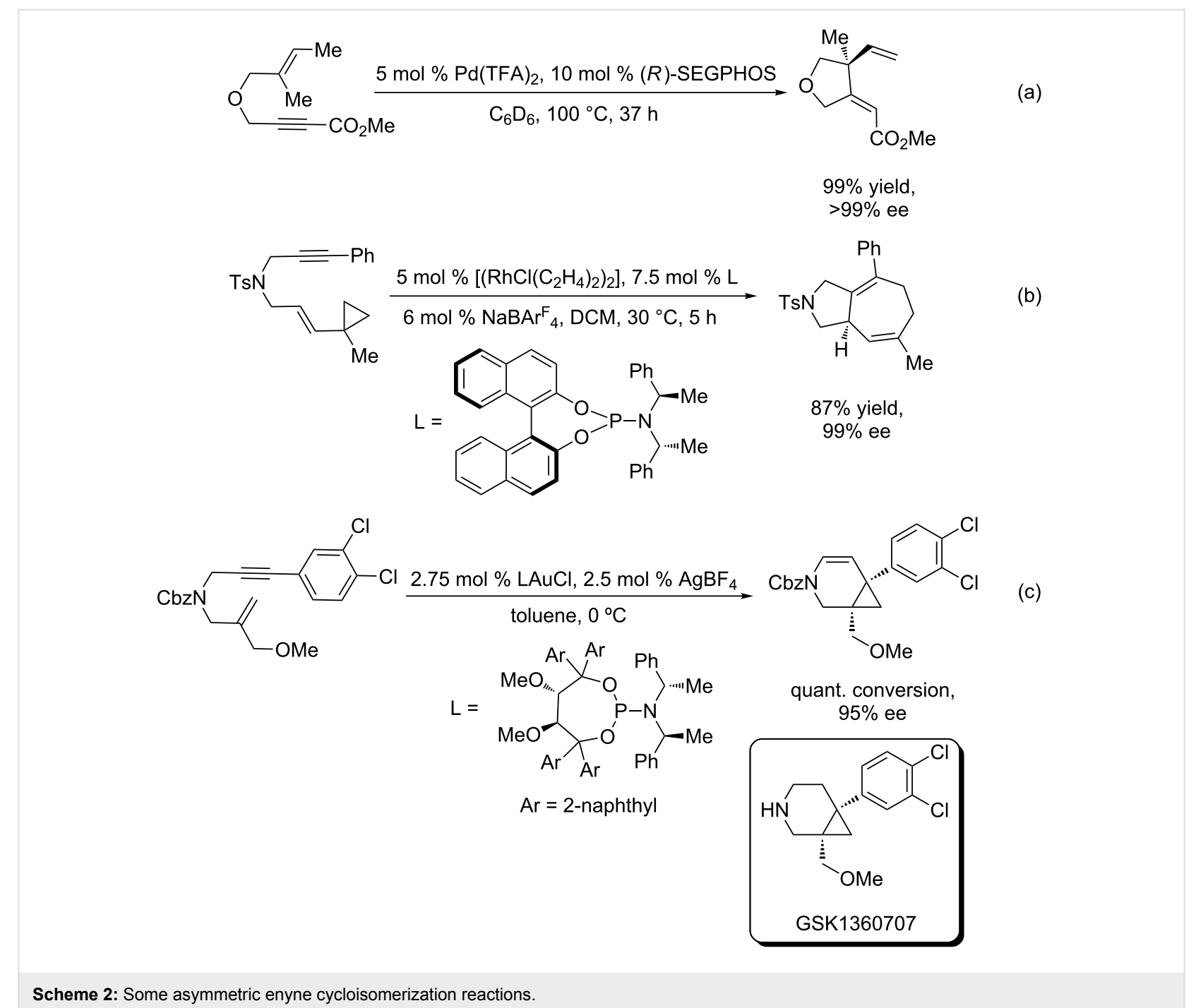

gold catalysis would be particularly suited for the construction of the [4.1.0] bicyclic piperidine core of GSK1360707 [27], a triple-uptake inhibitor developed by GlaxoSmithKline [28,29] (Scheme 2c). The construction of this interesting molecular scaffold was a motivator of much of our early work on the ruthenium-catalyzed redox bicycloisomerization reaction (vide infra). Unlike ruthenium and palladium enyne cycloisomerization, which operate via metallacycle formation or hydrometallation, gold acts as a $\pi$-acid, increasing the electrophilicity of the alkyne by $\eta^{2}$ coordination. The pendant alkene cyclizes on the alkyne, and the resulting tertiary carbocation is trapped by a gold carbenoid intermediate to form the fused cyclopropane.

While there had been reports of utilizing chiral ruthenium complexes for asymmetric catalysis prior to our studies [30-40], there had previously been no reported examples of asymmetric ruthenium-catalyzed cycloisomerization reactions in the literature. In 2011, our research group disclosed the ruthenium-cata- lyzed redox bicycloisomerization of 1,6- and 1,7-enynes to construct structurally complex [3.1.0] and [4.1.0] bicycles containing vicinal, quaternary all-carbon stereocenters [41] (Figure 1a). The proposed mechanism of this fascinating reaction involves chloride abstraction of the ruthenium catalyst by indium(III) triflate and phosphine ligand dissociation. The propargyl alcohol then coordinates to the now coordinatively unsaturated cyclopentadienylruthenium $(\mathrm{CpRu})$ fragment in a bidentate fashion and undergoes a redox isomerization reaction wherein the carbinol proton performs a 1,2-hydride shift. The resulting vinylruthenium intermediate can be seen as a resonance structure of a ruthenium carbene, which coordinates to a pendant alkene, performs a $[2+2]$ cycloaddition to form a ruthenacyclobutane, and reductively eliminates to generate the bicyclic product.

Intrigued by the possibility of rendering this reaction asymmetric, we wondered if an appropriate choice of catalyst, 


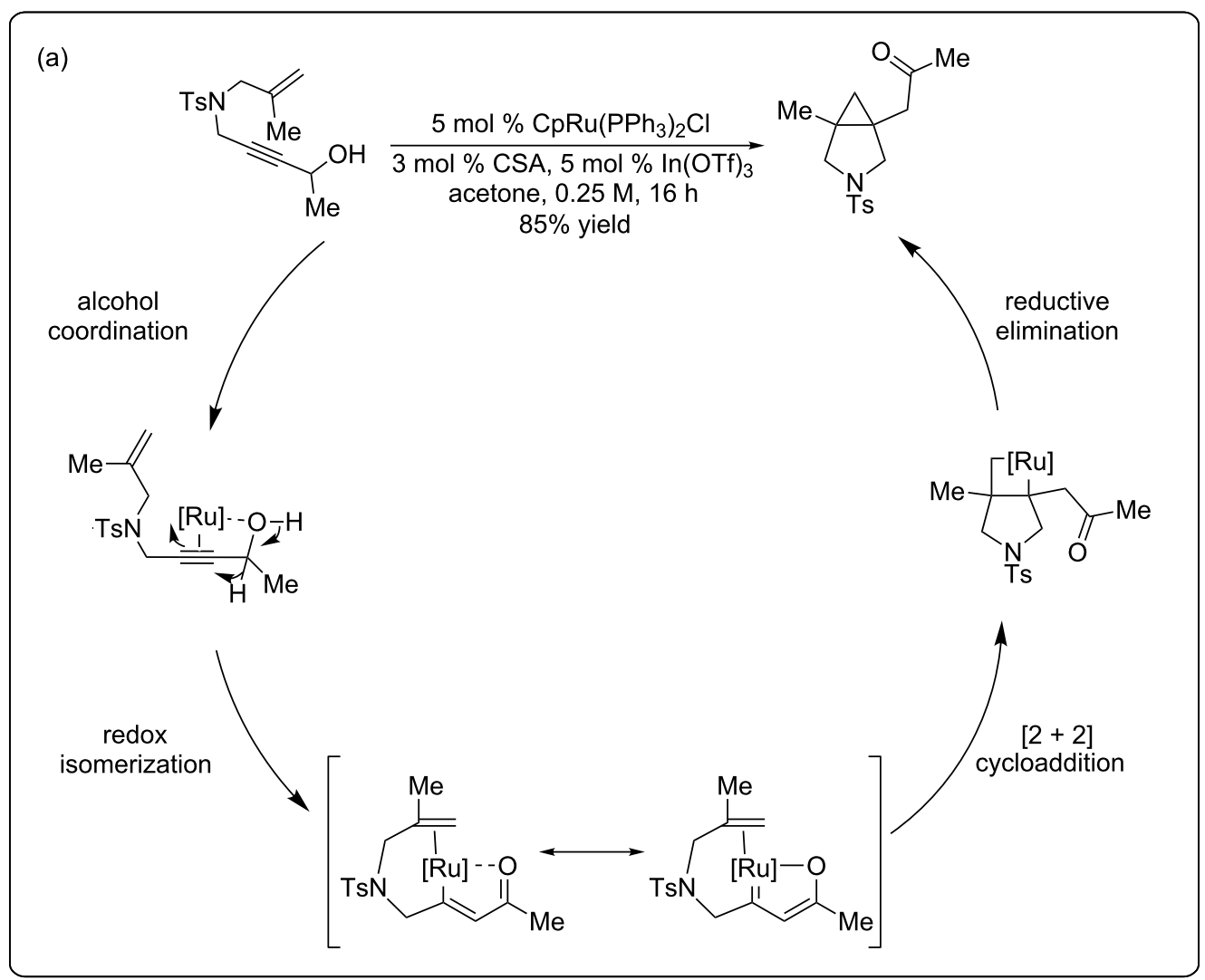

(b)

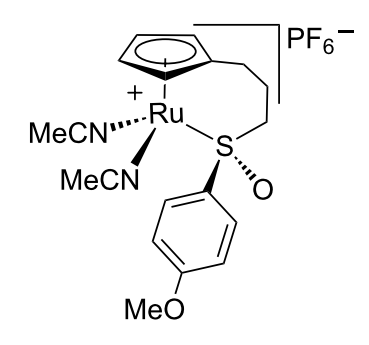

(c)<smiles>[R]C#C[C@]([3H])(O[C@@H]([R])C)C1C=CC=C1</smiles><smiles>[R]C#C[R1]1([H])C=CCC1</smiles>

1

chiral-at-Ru complexes $L^{*}=$ chiral ligand

Figure 1: (a) Mechanism for the redox biscycloisomerization reaction. (b) Ruthenium catalyst containing a tethered chiral sulfoxide. (c) Possible diastereomeric complexes formed from alcohol coordination.

namely the chiral $\mathrm{CpRu}$-sulfoxide catalysts $\mathbf{1}$ our group developed for asymmetric allylic substitution reactions [42] (Figure 1b), would be able to impart sufficiently useful enantioselectivities on these complex, drug-like molecules. While the idea certainly was appealing at first glance, this reaction is complicated by the fact that the 1,6- and 1,7-enyne substrates contain a stereogenic center that, upon coordination to ruthenium, create diastereomeric, chiral-at-ruthenium complexes (Figure 1c). It was unclear a priori whether this transfer of stereochemical information would have an adventitious, negligible, or detrimental impact on the enantioselectivity of the reaction. With this important consideration in mind, we began our search for an asymmetric ruthenium-catalyzed redox bicycloisomerization reaction [43].

\section{Results and Discussion Catalyst synthesis}

Synthesis of CpRu-sulfoxide complexes requires a six-step sequence that was developed in our group [44]. Scheme 3 outlines the synthetic sequence of $p$-anisyl catalyst $\mathbf{1}$. In situ reduction of 4-methoxysulfonyl chloride by triphenylphosphine and trapping with (-)-menthol affords diastereomerically pure sulfinate ester 2 after enrichment by recrystallization [45]. Grignard addition attaches a TMS-protected alkyne of appropriate tether 


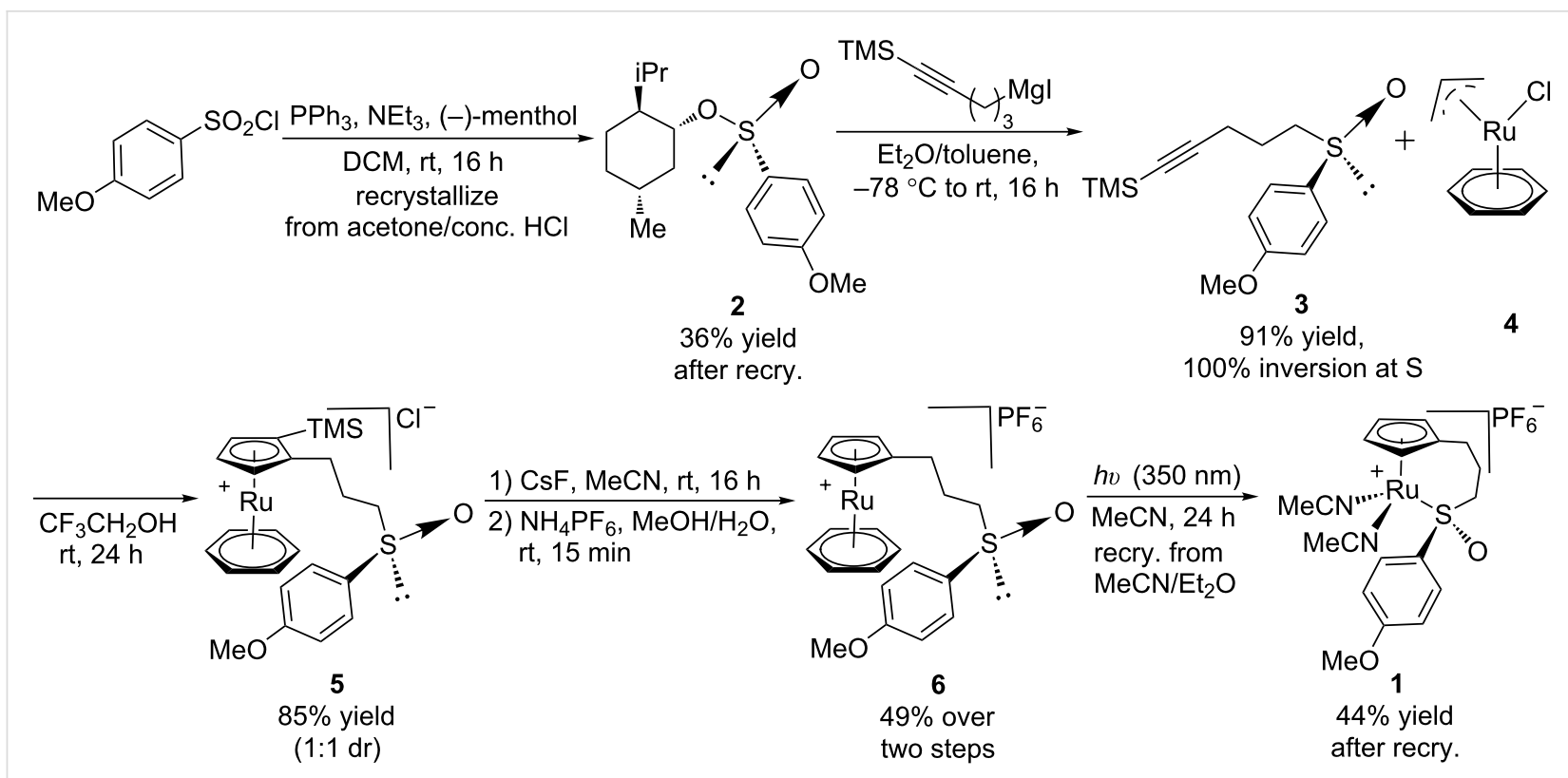

Scheme 3: Synthesis of $p$-anisyl catalyst 1.

length via stereospecific nucleophilic displacement of the chiral auxiliary with complete inversion of configuration at the sulfur center [46,47]. Sulfoxide 3 is incorporated into the catalyst via a $[3+2]$ oxidative cycloaddition with allylruthenium complex 4 . Desilylation of cationic complex $\mathbf{5}$, ion exchange, and photolysis of 6 completes the synthesis of catalyst 1. Using this strategy, a variety of catalysts including $p$-tolyl, 2-naphthyl, 1-naphthyl, and tert-butyl sulfoxide complexes were all synthesized in an analogous fashion. This method has a distinct advantage over a traditional $\mathrm{CpRu}$ catalyst synthesis in that the complexes can be made quickly and efficiently without relying on toxic thallium salts to transfer substitutionally complex cyclopentadienyl ligands to ruthenium.
While certainly attractive, the main limitation to this synthetic route is that the diastereomeric mixture of sulfinate esters made in the first step is required to either be a solid that can be recrystallized to diastereomeric purity or be separable by column chromatography. Figure 2 contains the attempted sulfinate ester syntheses that failed using the method described in Scheme 3. An alternate method to synthesize these chiral sulfoxides needed to be explored, preferably one that did not rely on crystallization.

In 2005, the Senanayake group described a process in which $(+)$-norephedrine-derived oxathiazolidine 2-oxides are used as sulfinyl transfer agents in the synthesis of optically pure sulfox-<smiles>[R]O[Sb](C)(O)c1cc(Cl)cc(Cl)c1</smiles><smiles>COc1ccc(S(C)(O)O)c(OC)c1</smiles><smiles>[X]O[Sb](C)(O)c1cc(C(F)(F)F)cc(C(F)(F)F)c1</smiles><smiles>[X]O[Si](O)(O)c1c(F)c(F)c(F)c(F)c1F</smiles><smiles>O=[Sb](O)(O)c1cccc(F)c1</smiles>

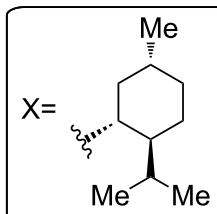<smiles>CC1OC(C)(C)OC1OC1C(C)OC(C)C1C</smiles>

Menthyl

DDG

$\mathrm{X}$ indicates both Menthyl and DDG auxilliary tried.

Figure 2: Failed sulfinate ester syntheses. 
ides and sulfinamides [48]. The application of this method to the synthesis of our chiral sulfoxide tethers is presented in Scheme 4. Tosyl protection of the primary amine of $(+)$-norephedrine and treatment with thionyl chloride furnishes chiral oxathiazolidine 2-oxide 7 as a single diastereomer in $87 \%$ yield over two steps. Heterocycle 7 is a bench stable white powder that can be stored indefinitely in a dessicator without any noticeable decomposition. The sulfonamide moiety activates sulfur towards nucleophilic addition, making the first addition of an organometallic reagent faster than the second. By performing two successive organometallic additions to 7 , one could in principle obtain any desired chiral sulfoxide. Addition of a slight excess of (5-trimethylsilyl)-4-pentynylmagnesium iodide to the auxiliary at $-78{ }^{\circ} \mathrm{C}$ affords sulfinate ester 8 in a $66 \%$ yield and as a single diastereomer. Organocuprate addition to $\mathbf{8}$ completes the synthesis of tether precursors $\mathbf{9}$ and $\mathbf{1 0}$. The use of an organocuprate is essential in order to obtain good yields of the desired sulfoxides; the enantiospecificity of this organocuprate addition was checked by comparison of the optical rotation of $\mathbf{3}$ synthesized by this method with $\mathbf{3}$ synthesized by the menthyl sulfinate ester method used in Scheme 3. The o-anisyl sulfoxide $\mathbf{1 2}$ had to be synthesized in a slightly different manner because the organocuprate addition to $\mathbf{8}$ failed, most likely due to deactivation of the organometallic by the proximal methoxy group. Instead, sulfinate ester 11 was synthesized and subjected to alkylation with (5-trimethylsilyl)-4pentynylmagnesium iodide. Because the order of addition was reversed, it is important to note that $\mathbf{1 2}$ has the opposite absolute configuration. In this way, sulfoxides containing $m$-xylyl, $o$-methoxyphenyl, and cyclohexyl groups have been made and carried through the remainder of the standard catalyst synthesis as outlined in Scheme 3. None of the catalysts made through this method could be synthesized through separation of sulfinate ester diastereomers.

\section{Substrate synthesis}

The substrates for the enyne bicycloisomerization reaction can be readily accessed in two steps. Alkylation of a secondary propargylamide can be achieved by sodium hydride deprotonation of its acidic proton and $\mathrm{S}_{\mathrm{N}} 2$ substitution of a substituted propargyl bromide (Scheme 5a). Alternatively, the same propargylamide can be alkylated under Mitsunobu conditions with a desired primary alcohol. One such alcohol, 2-cyclopropylprop-2-en-1-ol, can be synthesized using a modified Suzuki coupling procedure developed by Soderquist [49] (Scheme 5b). A cyclopropyl boronate can be generated from propargyl bromide, 9-BBN, and aqueous sodium hydroxide. This reactive intermediate can be used in situ for the subsequent coupling reaction, which constructs the desired allyl alcohol after deprotection in a $52 \%$ yield over two steps. After alkylation, the newly-formed enynes can then be deprotonated with either $n$-BuLi or LiHMDS and trapped with an aldehyde to form a substituted propargyl alcohol. With a convenient route towards these enyne substrates in hand, we set our sights on optimizing the asymmetric enyne bicycloisomerization reaction.

\section{Initial experiments and reaction optimization}

Due to the similarity of $\mathbf{1 4}$ to the triple-uptake inhibitor GSK1360707 (see Scheme 2), we decided to initiate our efforts on 1,7-enyne sulfonamide $\mathbf{1 3}$ for reaction optimization. Table 1 showcases our initial experiments. With $3 \mathrm{~mol} \%$ of CpRu-sulfoxide catalyst 1 in THF at $40{ }^{\circ} \mathrm{C}, 14$ could be obtained in a $69 \%$ yield and a promising 26.5:73.5 er (Table 1, entry 1). This important first experiment establishes that 1 not only efficiently catalyzes redox bicycloisomerization, but also that the ligated chiral sulfoxide can induce asymmetry in the [4.1.0] bicyclic product. Indeed, we have shown through control experiments that $\mathrm{CpRu}(\mathrm{MeCN})_{3} \mathrm{PF}_{6}$ does not catalyze this reaction without added ligands, implying that the sulfoxide must be bound to the

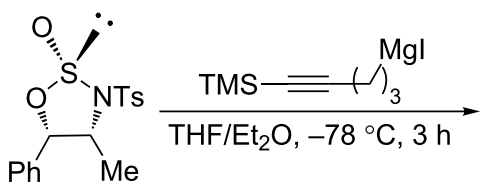

7<smiles>[13CH3]S1(O)[NH2+][CH]C(c2ccccc2)O1</smiles>

7

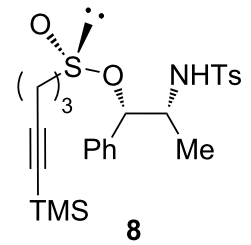

$66 \%$ yield, $>99: 1 \mathrm{dr}$

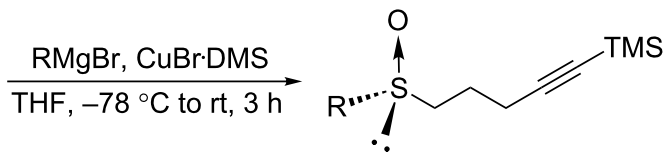

$\mathrm{R}=m$-xylyl, 9, 72\% yield cyclohexyl, 10, $70 \%$ yield

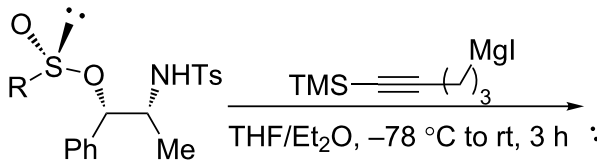

$\mathrm{R}=0$-anisyl, 11

$66 \%$ yield, $>99: 1 \mathrm{dr}$

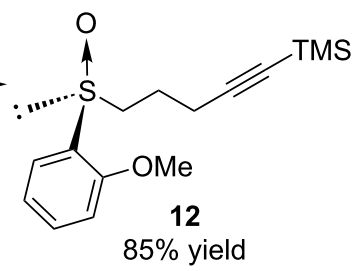




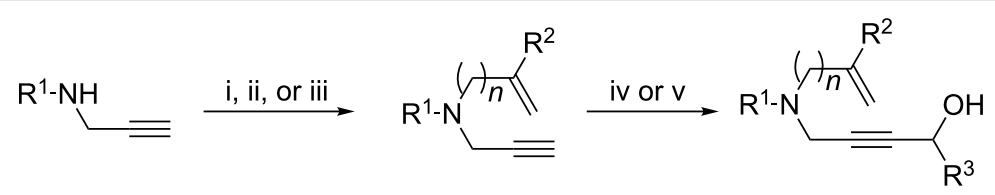

Conditions: i. $\mathrm{NaH}$, DMSO, rt, then alkyl bromide, $14 \mathrm{~h}$. ii) $\mathrm{NaH}, \mathrm{DMF}, 0^{\circ} \mathrm{C}$, then alkyl bromide, $0^{\circ} \mathrm{C}$ to rt, $17 \mathrm{~h}$. iii) Alcohol, $\mathrm{PPh}_{3}$, DIAD, THF, rt, $17 \mathrm{~h}$. iv) LiHMDS, THF, $-78^{\circ} \mathrm{C}, 30 \mathrm{~min}$ then $\mathrm{R}^{3} \mathrm{CHO},-78^{\circ} \mathrm{C}, 1 \mathrm{~h}$. v) $n$-BuLi, THF, $-78^{\circ} \mathrm{C}, 30 \mathrm{~min}$ then $\mathrm{R}^{3} \mathrm{CHO},-78^{\circ} \mathrm{C}, 1 \mathrm{~h}$.

$$
\mathrm{Br}_{\mathrm{Br}} \frac{\text { 1) } 2 \text { equiv 9-BBN, THF, reflux, } 2 \mathrm{~h}}{\text { 2) } 3 \mathrm{M} \mathrm{NaOH}, \mathrm{rt}, 1 \mathrm{~h}}
$$

(b)

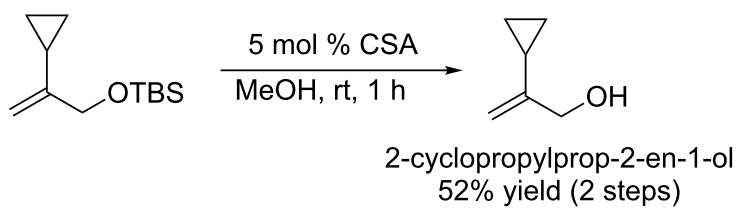

Scheme 5: (a) General synthetic sequence to access enyne bicycloisomerization substrates (b) Synthesis of 2-cyclopropylprop-2-en-1-ol using a modified Suzuki coupling reaction developed by Soderquist.

Table 1: Initial result for the asymmetric redox bicycloisomerization of 1,7-enyne 13 with chiral CpRu-sulfoxide complex 1 and the effect of added ligands.

\begin{tabular}{|c|c|c|c|c|c|}
\hline entry & ligand & temp. $\left({ }^{\circ} \mathrm{C}\right)$ & conversion $(\%)^{a}$ & yield $(\%)$ & $e r^{b}$ \\
\hline 1 & none & 40 & 100 & 69 & $26.5: 73.5$ \\
\hline 2 & none & 60 & 100 & 89 & $26.0: 74.0$ \\
\hline 3 & $\mathrm{PPh}_{3}$ & 60 & 0 & n.r. & - \\
\hline 4 & $\mathrm{P}(\mathrm{OPh})_{3}$ & 60 & 0 & n.r. & - \\
\hline 5 & $(+)-(R)$-methyl $p$-tolyl sulfoxide & 60 & 100 & 74 & $28.0: 72.0$ \\
\hline 6 & $(+)-(R)$-methyl $p$-tolyl sulfoxide & 40 & 50 & 22 & $41.5: 58.5$ \\
\hline 7 & $(-)-(S)$-methyl $p$-tolyl sulfoxide & 40 & 0 & N.R. & - \\
\hline 8 & $( \pm)-N$-(p-tosyl) methyl $p$-tolyl sulfimide & 40 & 50 & 22 & $50.0: 50.0$ \\
\hline
\end{tabular}

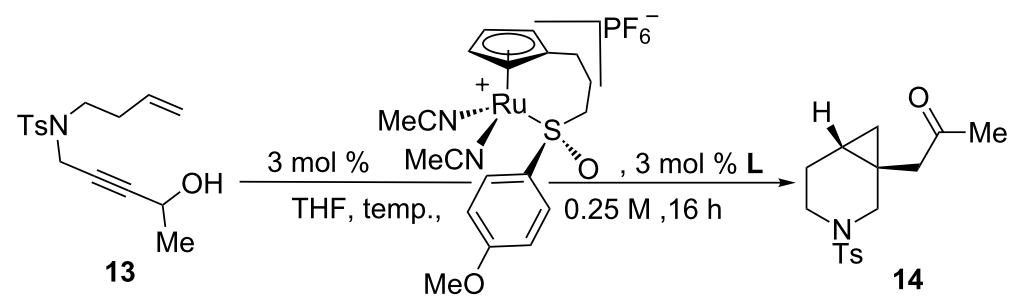

aDetermined by NMR integration. ${ }^{b}$ Determined by chiral HPLC.

metal in order for the reaction to proceed. Raising the temperature to $60{ }^{\circ} \mathrm{C}$ had a negligible impact on enantioselectivity (Table 1, entry 2).

Our proposed mechanism of the racemic redox bicycloisomerization reaction necessitates the decomplexation of one phos- phine ligand before catalysis can occur (vide supra). In other words, ruthenium must have two open coordination sites in order to bind the substrate. To test if there is a similar requirement for $\mathbf{1}$, we decided to add one catalyst equivalent of an auxiliary ligand to test its impact on reaction rate, conversion, and enantioselectivity. Added phosphorous-based ligands only 
served to completely shut down all reactivity (Table 1 , entries 3 and 4$)$. At $60{ }^{\circ} \mathrm{C}, 3 \mathrm{~mol} \%$ of chiral $(+)-(R)$-methyl $p$-tolyl sulfoxide had no impact on the reaction, indicating negligible binding of the ligand to the metal (Table 1, entry 5). In general, untethered, exogenous sulfoxides are poorer ligands to ruthenium than phosphines or phosphites. As the reaction temperature is lowered to $40{ }^{\circ} \mathrm{C}$, however, one begins to see a significant decrease in reaction rate and conversion (Table 1, entry 6). The enantioselectivity of the reaction also drops to 41.5:58.5 er Interestingly, (-)-(S)-methyl $p$-tolyl sulfoxide completely inhibited any reaction at $40{ }^{\circ} \mathrm{C}$ (Table 1 , entry 7). Finally, the more electron-withdrawing $( \pm)-N$ - $p$-tosyl methyl $p$-tolyl sulfimide $\left(p-\mathrm{CH}_{3} \mathrm{Ph}(\mathrm{S}=\mathrm{NTs}) \mathrm{CH}_{3}\right)$ also reduced both conversion and er.

As seen in Table 2, the redox bicycloisomerization reaction is compatible with a number of solvents that have vastly different steric profiles and dielectric constants. The nature of the solvent also had a significant impact on the enantiomeric ratios. Switching from THF to acetone, we observed a dramatic reversal in enantioselectivity, going from 26.5:73.5 to 67.0:33.0, respectively (Table 2, entry 2). Changing the reaction temperature had no impact on the er, similar to the temperature studies done in THF (Table 2, entries 3 and 4).
Initially, we thought that this difference in selectivity between acetone and THF was due to their drastically different steric profiles, so we tested bulkier analogues of these solvents, 2,5dimethyl THF (mixture of cis and trans, entry 5) and 3-methyl2-butanone (Table 2, entry 6). Complex 1 catalyzed the redox bicycloisomerization reaction less efficiently in both solvents. Chlorinated (Table 2, entry 7), aromatic (entry 8), ester (entry 9), and alcohol (entry 10) solvents were all tried, with inferior results to acetone and THF and without any obvious trends in selectivity apparent. Finally, alternative ethereal solvents like 1,4-dioxane (Table 2, entry 11) and DME (entry 12) were checked, as well as the effect of adding a small volume percentage of $N, N$-dimethylformamide (Table 2, entries 13 and 14). No improvement in enantioselectivity was observed.

The effect of catalyst structure on the selectivity of the redox bicycloisomerization reaction was explored in both acetone and THF, due to the differential nature of both of these solvents (Table 3). $p$-Tolyl and 2-naphthyl sulfoxide complexes 15 and 16 were both able to catalyze the reaction to complete conversion, although the enantiomeric ratios of $\mathbf{1 4}$ were lower than in the $p$-anisyl case. Curiously, the bulkier 1-naphthyl sulfoxide complex 17 was completely ineffective, most likely due to deli-

Table 2: Solvent effects on asymmetric redox bicycloisomerization reaction as described in [43]

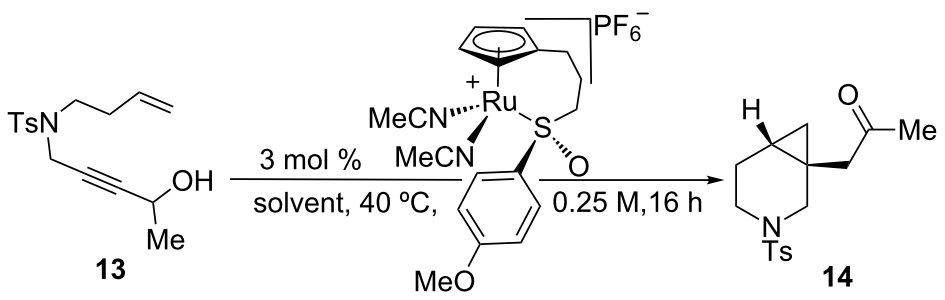

\begin{tabular}{|c|c|c|c|c|}
\hline entry & solvent & conversion $(\%)^{a}$ & yield (\%) & $e r^{b}$ \\
\hline 1 & THF & 100 & 69 & 26.5:73.5 \\
\hline 2 & acetone & 100 & 72 & 67.0:33.0 \\
\hline $3^{c}$ & acetone & 100 & 69 & 67.0:33.0 \\
\hline $4^{d}$ & acetone & 91 & n.d. ${ }^{e}$ & 66.0:34.0 \\
\hline $5^{c}$ & $2,5-\mathrm{Me}_{2} \mathrm{THF}^{\mathrm{f}}$ & 50 & 17 & $26.5: 73.5$ \\
\hline $6^{c}$ & iPr Me ketone & 70 & 47 & 57.5:42.5 \\
\hline 7 & DCE & 100 & 66 & 60.5:39.5 \\
\hline 8 & toluene & 59 & n.d. ${ }^{e}$ & $31.5: 68.5$ \\
\hline 9 & EtOAc & 100 & 65 & $37.0: 63.0$ \\
\hline 10 & $\mathrm{MeOH}$ & 100 & 80 & $45.0: 55.0$ \\
\hline 11 & 1,4-dioxane & 100 & 59 & $32.0: 68.0$ \\
\hline 12 & DME & 100 & 56 & $27.0: 73.0$ \\
\hline 13 & THF $^{\mathrm{g}}$ & 62 & 13 & 41.0:59.0 \\
\hline 14 & acetone $^{\mathrm{g}}$ & 88 & 56 & 61.0:39.0 \\
\hline
\end{tabular}

aDetermined by NMR integration. ${ }^{b}$ Determined by chiral HPLC. ${ }^{\mathrm{c}}$ Reaction performed at 60 degrees. ${ }^{\mathrm{d}}$ Reaction performed at room temperature. ${ }^{\mathrm{e}} \mathrm{Not}$ determined due to inseparability from starting substrate. fMixture of cis and trans. ${ }^{9} 2$ vol \% DMF added. 
Table 3: Effect of the catalyst structure on the redox bicycloisomerization as described in [43].

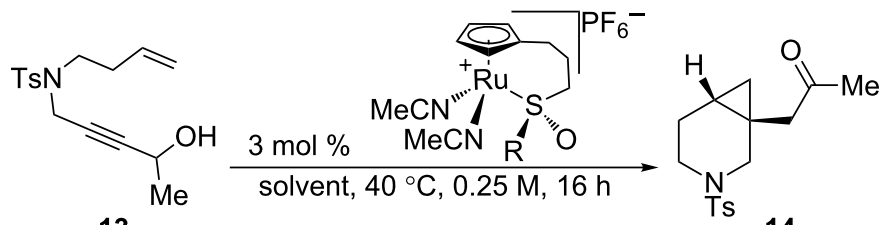

13

14

\begin{tabular}{|c|c|c|c|c|c|}
\hline entry & $\mathrm{R}$ & solvent & conversion (\%)a & yield (\%) & $e r^{b}$ \\
\hline 1 & & $\begin{array}{c}\text { acetone } \\
\text { THF }\end{array}$ & $\begin{array}{l}100 \\
100\end{array}$ & $\begin{array}{l}72 \\
69\end{array}$ & $\begin{array}{l}\text { 67.0:33.0 } \\
26.5: 73.5\end{array}$ \\
\hline 2 & & $\begin{array}{c}\text { acetone } \\
\text { THF }\end{array}$ & $\begin{array}{l}100 \\
100\end{array}$ & $\begin{array}{l}72 \\
53\end{array}$ & $\begin{array}{l}\text { 64.5:35.5 } \\
41.0: 59.0\end{array}$ \\
\hline 3 & & $\begin{array}{c}\text { acetone } \\
\text { THF }\end{array}$ & $\begin{array}{l}100 \\
100\end{array}$ & $\begin{array}{l}72 \\
58\end{array}$ & $\begin{array}{l}\text { 60.5:39.5 } \\
31.5: 68.5\end{array}$ \\
\hline 4 & & $\begin{array}{c}\text { acetone } \\
\text { THF }\end{array}$ & $\begin{array}{l}0 \\
0\end{array}$ & $\begin{array}{l}\text { n.r. } \\
\text { n.r. }\end{array}$ & - \\
\hline 5 & & $\begin{array}{c}\text { acetone } \\
\text { THF }\end{array}$ & $\begin{array}{c}100 \\
93\end{array}$ & $\begin{array}{l}69 \\
44\end{array}$ & $\begin{array}{l}40.5: 59.5 \\
43.5: 56.5\end{array}$ \\
\hline 6 & & $\begin{array}{c}\text { acetone } \\
\text { THF }\end{array}$ & $\begin{array}{l}50 \\
82\end{array}$ & $\begin{array}{l}11 \\
36\end{array}$ & $\begin{array}{l}52.0: 48.0 \\
54.0: 46.0\end{array}$ \\
\hline $7^{c}$ & & $\begin{array}{c}\text { acetone } \\
\text { THF }\end{array}$ & $\begin{array}{c}100 \\
63\end{array}$ & $\begin{array}{l}50 \\
30\end{array}$ & $\begin{array}{l}27.5: 72.5 \\
22.0: 78.0\end{array}$ \\
\hline 8 & & $\begin{array}{c}\text { acetone } \\
\text { THF }\end{array}$ & $\begin{array}{l}100 \\
100\end{array}$ & $\begin{array}{l}70 \\
57\end{array}$ & $\begin{array}{l}73.5: 26.5 \\
47.5: 52.5\end{array}$ \\
\hline
\end{tabular}

aDetermined by NMR integration. betermined by chiral HPLC. ${ }^{\mathrm{c} C a t a l y s t ~ e n a n t i o m e r ~ o p p o s i t e ~ t o ~ t h e ~ o n e ~ s h o w n . ~}$

gation of the sulfoxide prior to coordination of the substrate (Table 3, entry 4). The more electron-rich, bulky $t$-butyl sulfoxide catalyst $\mathbf{1 8}$, was able to maintain coordination to ruthenium, though the enantiomeric ratios obtained were unsatisfactory (Table 3 , entry 5). $m$-Xylyl 19 was similarly disappointing (Table 3, entry 6). However, $o$-anisyl 20 was interesting in that it was able to maintain high enantiomeric ratios of $\mathbf{1 4}$ in both
THF and acetone and with the same absolute configuration (Table 3, entry 7). This could possibly be due to a chelation effect wherein the $o$-methoxy group acts as a hemilabile ligand, changing the steric and electronic environment around the metal center. Since 20 displayed inferior conversions and yields, however, it was eschewed in favor of complex 1. Cyclohexyl 21 was also an excellent catalyst in terms of reactivity, but again 
this system did not prove to be differential towards the enantiomeric ratio of $\mathbf{1 4}$.

Before moving forward with complex 1, we wondered how these complexes compare to other catalyst/ligand systems in terms of reactivity (Table 4). After all, complexing an achiral, commercially available catalyst $\mathrm{CpRu}(\mathrm{MeCN})_{3} \mathrm{PF}_{6}$ with a chiral ligand would constitute a much simpler solution to the development of an asymmetric redox bicycloisomerization reaction. To compare the efficiency of each catalyst system, we decided to run the reaction for a shorter period of time, stop the reaction, and check the conversion by proton NMR.

As seen in Table 4, when this experiment is performed with 3 mol \% complex 1 , a $54 \%$ conversion is observed after 1.5 hours (entry 1 ). When the same experiment is conducted with $3 \mathrm{~mol} \%$ of $\mathrm{CpRu}(\mathrm{MeCN})_{3} \mathrm{PF}_{6}$ and $3 \mathrm{~mol} \%$ triphenylphosphine, the reaction only proceeds to $15 \%$ conversion, indicating that the tethered sulfoxide complex is much more efficient at catalyzing redox bicycloisomerization (Table 4, entry $2)$. As one would expect from the lessons learned in the previous studies, chiral bidentate $(R)$-BINAP completely inhibits any reactivity (Table 4 , entry 3 ). Surprisingly, monodentate $(S, S, R)$-Feringa was also an ineffective ligand for this process, which underscores the stringent electronic requirements a ligand must have in order to promote redox bicycloisomerization (Table 4, entry 4). To date, the only effective ligands for redox bicycloisomerization have been triaryl phosphines, biaryl sulfoxides, or monoaryl monoalkyl sulfoxides. After 1.5 hours, $(S)$-methyl $p$-tolyl sulfoxide also showed no conversion (Table 4 , entry 5 ).
Since subtle changes in the structure of the enyne substrate could have a significant impact on enantioselectivity, variations of the substituent on nitrogen were examined (Table 5). These reactions were conducted in THF, as this solvent provided the highest enantioselectivities in the [4.1.0] system. Incorporating electron rich or electron poor aromatics on the sulfonamide resulted in diminished reactivities and selectivities, as seen in the cases of entries 2 and 3 (Table 5). Surprisingly, 2-biphenyl sulfonamide 26 gave an unimproved 26.0:74.0 er, despite the increased steric bulk on the substrate (Table 5, entry 4). Further increasing the Lewis basicity of the nitrogen completely shuts down catalyst activity, as can be seen in the case of the benzhydryl tertiary amine $\mathbf{2 8}$ (Table 5, entry 5). Phosphoramidate $\mathbf{3 1}$ could be obtained in good yield and with an increased enantioselectivity when compared to the parent sulfonamide (Table 5, entry 6). Amide 32 also reacted, but with a lower conversion and yield, possibly due to increased coordination of the amide to the Lewis acidic ruthenium center (Table 5, entry 7). Gratifyingly, utilizing the bulkier 2,4,6-triisopropylbenzenesulfonyl group (Tris) significantly improved the er of protected piperidine 35 to 15.0:85.0. Because of its differential impact on selectivity, this protecting group was pursued more broadly in the substrate scope.

\section{Substrate scope}

Unfortunately, the conditions developed for the Tris-protected [4.1.0] bicycle 35 did not extend to other similarly protected 1,7-enynes [43]. We decided to shift our focus from 1,7- to 1,6enynes to determine if bicyclic [3.1.0] pyrrolidines are more broadly accessible to our synthetic method (Table 6). While the 1,6-enyne substrates $\mathbf{3 6}$ and $\mathbf{3 8}$ exhibited the desired reactivity

Table 4: Comparison of complex 1 to other catalyst systems as described in [43].

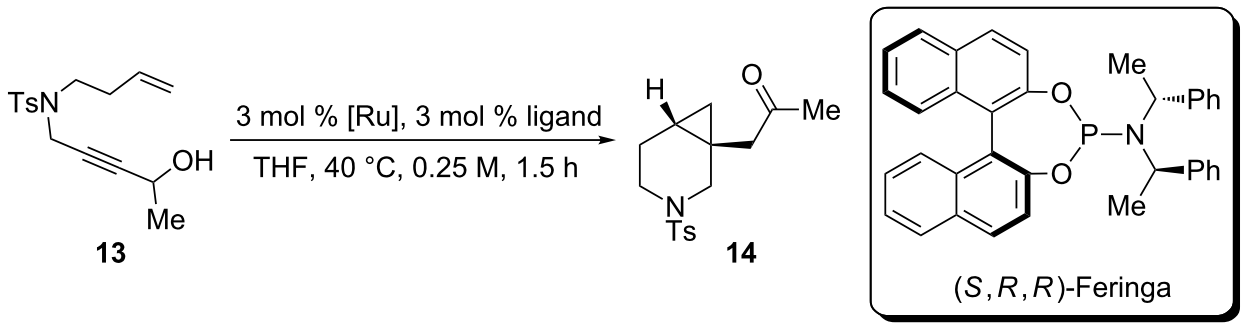

\begin{tabular}{cccc}
\hline entry & {$[\mathrm{Ru}]$} & ligand & conversion $(\%)^{\mathrm{a}}$ \\
\hline 1 & $\mathbf{1}$ & none & 54 \\
2 & $\mathrm{CpRu}(\mathrm{MeCN})_{3} \mathrm{PF}_{6}$ & $\mathrm{PPh}_{3}$ & 15 \\
3 & $\mathrm{CpRu}(\mathrm{MeCN})_{3} \mathrm{PF}_{6}$ & $(R)$-BINAP & 0 \\
4 & $\mathrm{CpRu}(\mathrm{MeCN})_{3} \mathrm{PF}_{6}$ & $(S, S, R)$-Feringa & 0 \\
5 & $\mathrm{CpRu}(\mathrm{MeCN})_{3} \mathrm{PF}_{6}$ & $(S)$-methyl $p$-tolyl sulfoxide & 0 \\
\hline
\end{tabular}

aDetermined by ${ }^{1} \mathrm{H}$ NMR. 
Table 5: Effect of the nitrogen protecting group on reactivity and enantioselectivity as described in [43].

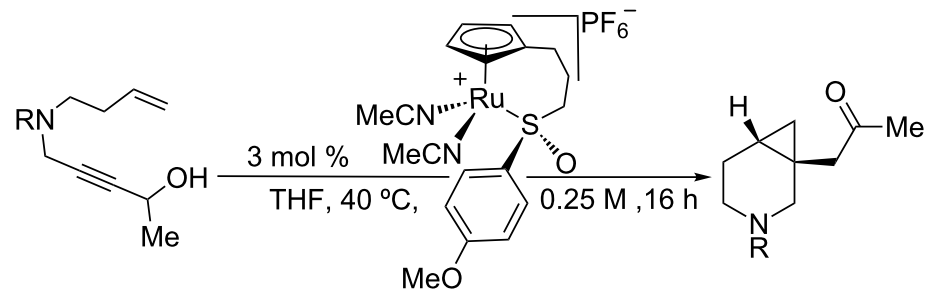

\begin{tabular}{|c|c|c|c|c|c|}
\hline entry & $\mathrm{R}$ & substrate & product & yield $(\%)$ & $\mathrm{er}^{\mathrm{a}, \mathrm{b}}$ \\
\hline 1 & & 13 & 14 & 69 & $26.5: 73.5$ \\
\hline 2 & & 22 & 23 & 21 & $31.5: 68.5$ \\
\hline 3 & & 24 & 25 & n.d. ${ }^{c}$ & $43.5: 56.5$ \\
\hline 4 & & 26 & 27 & 59 & $26.0: 74.0$ \\
\hline 5 & & 28 & 29 & n.r. ${ }^{d}$ & - \\
\hline 6 & & 30 & 31 & 52 & $21.0: 79.0$ \\
\hline 7 & & 32 & 33 & $45^{\mathrm{e}}$ & 26.5:73.5 \\
\hline 8 & & 34 & 35 & 56 & $15.0: 85.0$ \\
\hline
\end{tabular}

aDetermined by chiral HPLC. ${ }^{b}\left(\right.$ Enantiomer A:Enantiomer B). Absolute configuration not determined. Bold indicates major enantiomer. ${ }^{\mathrm{c}} \mathrm{n} . \mathrm{d} .=\mathrm{not}^{\mathrm{a}} \mathrm{de}^{-}$ termined. Conversion $\sim 30 \%$. ${ }^{d}$.r. $=$ no reaction. ${ }^{e}$ Conversion $\sim 50 \%$.

in THF, the enantioselectivities for the process were poor. Considering how impactful a judicious choice of solvent had on the enantioselectivity of the [4.1.0] bicycles, we decided to try the same reactions in acetone. Pleasingly, exceptional yields and enantioselectivities of $\mathbf{3 7}$ and $\mathbf{3 9}$ were obtained in this solvent, surpassing those obtained for 35. Catalyst 1 exhibits excellent functional group compatibility. Substrates containing remote electron-neutral aromatic rings $\mathbf{4 0}$, alkenes $\mathbf{4 2}$, and alkynes $\mathbf{4 4}$ are all tolerated and remain intact under the reaction conditions. The reaction can also tolerate branching at the internal position of the pendant olefin, as polycyclic 46 and 48 displayed excellent enantiomeric ratios. It is also important to point out that no ring opening of either $\mathbf{4 9}$ or its vinylcyclopropane precursor $\mathbf{4 8}$ was observed. Finally, styrenyl substrates like 50 can be used for redox bicycloisomerization, but their pyrrolidine products are isolated in somewhat diminished enantioselectivities.

After examining the scope of the redox bicycloisomerization reaction for the synthesis of Tris-protected [3.1.0] pyrrolidines, 
Table 6: Tris-protected [3.1.0] bicyclic pyrrolidines made by redox bicycloisomerization ${ }^{a}$

\begin{tabular}{|c|c|c|c|c|c|c|}
\hline entry & $\mathrm{R}$ & $\mathrm{R}^{\prime}$ & enyne & product & Yield (\%) & er \\
\hline 1 & $\mathrm{Me}$ & $\mathrm{Me}$ & 36 & 37 & $\begin{array}{l}78 \\
85\end{array}$ & $\begin{array}{c}56.0: 44.0^{\mathrm{b}} \\
90.5: 9.5\end{array}$ \\
\hline 2 & $\mathrm{Me}$ & $\mathrm{iPr}$ & 38 & 39 & $\begin{array}{l}47 \\
75\end{array}$ & $\begin{array}{c}64.0: 36.0^{\mathrm{b}} \\
98.5: 1.5\end{array}$ \\
\hline $3^{c}$ & $\mathrm{Me}$ & $\mathrm{Bn}$ & 40 & 41 & 88 & $92.0: 8.0$ \\
\hline 4 & $\mathrm{Me}$ & $-\left(\mathrm{CH}_{2}\right)_{8} \mathrm{CH}=\mathrm{CH}_{2}$ & 42 & 43 & 57 & $93.0: 7.0$ \\
\hline $5^{d}$ & Me & $-\left(\mathrm{CH}_{2}\right)_{4} \mathrm{C} \equiv \mathrm{CH}_{3}$ & 44 & 45 & 48 & $90.0: 10.0$ \\
\hline 6 & cyclopentyl & $\mathrm{iPr}$ & 46 & 47 & 42 & $94.0: 6.0$ \\
\hline 7 & cyclopropyl & cyclohexyl & 48 & 49 & 75 & $90.0: 10.0$ \\
\hline 8 & $p$-tolyl & $\mathrm{Me}$ & 50 & 51 & 50 & $82.5: 17.5$ \\
\hline
\end{tabular}

a Tris $=2,4,6$-triisopropylbenzenesulfonyl. ${ }^{\mathrm{b}}$ Reaction conducted in THF. ${ }^{{ }^{5}} 5 \mathrm{~mol} \%$ of catalyst used. ${ }^{\mathrm{d}} 8.5 \mathrm{~mol} \%$ of catalyst used.

it occurred to us that protecting groups other than Tris may be equally effective for the [3.1.0] system. The Tris group was chosen during our optimization of the six-membered ring system (Table 5), which may have significantly different requirements necessary to achieve high enantioselectivity.
Indeed, when tosyl- or phosphoramidate-protected 1,6-enynes were tested, excellent yields and enantioselectivities were observed (Table 7). Like the Tris substrates, branching at the propargylic and alkenyl positions were well tolerated. Carbocyclic 69 could also be isolated with similar results, although

Table 7: Other substrate tethers for redox bicycloisomerization.

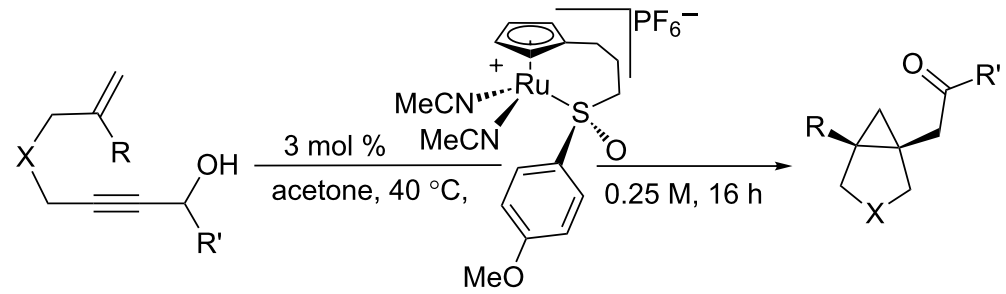

\begin{tabular}{|c|c|c|c|c|c|c|c|}
\hline entry & $x$ & $\mathrm{R}$ & $\mathrm{R}^{\prime}$ & enyne & product & yield (\%) & er \\
\hline 1 & -NTs & $\mathrm{Me}$ & $\mathrm{Me}$ & 52 & 53 & 81 & $94.0: 6.0$ \\
\hline 2 & -NTs & $\mathrm{Me}$ & $\mathrm{Bn}$ & 54 & 55 & 84 & $95.0: 5.0$ \\
\hline 3 & -NTs & cyclopentyl & $\mathrm{iPr}$ & 56 & 57 & 56 & $91.0: 9.0$ \\
\hline 4 & $-\mathrm{NP}(\mathrm{O})(\mathrm{OPh})_{2}$ & $\mathrm{Me}$ & $\mathrm{Me}$ & 58 & 59 & 84 & $98.0: 2.0$ \\
\hline $5^{a}$ & $-\mathrm{NP}(\mathrm{O})(\mathrm{OPh})_{2}$ & $\mathrm{Me}$ & $\mathrm{Bn}$ & 60 & 61 & 61 & $97.0: 3.0$ \\
\hline 6 & $-\mathrm{NP}(\mathrm{O})(\mathrm{OPh})_{2}$ & cyclopentyl & $\mathrm{iPr}$ & 62 & 63 & 64 & $96.0: 4.0$ \\
\hline 7 & $-\mathrm{NP}(\mathrm{O})(\mathrm{OPh})_{2}$ & $\mathrm{Me}$ & cyclohexyl & 64 & 65 & 51 & $96.0: 4.0$ \\
\hline 8 & $-\mathrm{NP}(\mathrm{O})(\mathrm{OPh})_{2}$ & $\mathrm{Ph}$ & $\mathrm{Me}$ & 66 & 67 & 69 & $88.0: 12.0$ \\
\hline $9^{b}$ & $-\mathrm{C}\left(\mathrm{CO}_{2} \mathrm{Bn}\right)_{2}$ & $\mathrm{Me}$ & $\mathrm{iPr}$ & 68 & 69 & 49 & $92.0: 8.0$ \\
\hline
\end{tabular}

${ }^{a} 5 \mathrm{~mol} \%$ of catalyst used. ${ }^{\mathrm{b}} 7.5 \mathrm{~mol} \%$ of catalyst used. 
the catalyst loading for this substrate had to be increased to $7.5 \mathrm{~mol} \%$. This is most likely due to the tendency of ruthenium to coordinate to certain aromatic rings in a $\eta^{6}$ fashion.

There were a few substrate classes that were not amenable to redox bicycloisomerization (Figure 3). For example, we thought that by increasing the steric bulk on styrenyl-substituted compound 50, either on the aromatic ring or at the propargylic position, the enantioselectivity would also increase. On the contrary, neither substrate $\mathbf{7 0}$ or $\mathbf{7 1}$ reacted at all, which indicated to us that this substrate class is very sensitive to steric substitution and where it is placed on the enyne. In other words, while both phenyl substitution and branching at the propargylic position are tolerated on separate enyne substrates (see for example $\mathbf{4 8}$ and 50), putting both moieties on the same substrate results in no reaction. Increasing steric congestion near the sulfonamide (substrate 72) also inhibits enyne bicycloisomerization, as does placing an additional alkyne in conjugation with the pendant alkene (substrate 73). Both cis- and trans-1,2-disubstituted alkenes $\mathbf{7 4}$ and $\mathbf{7 5}$ were observed to decompose under the standard reaction conditions.

The tosyl and 2,4,6-triisopropylbenzenesulfonyl groups on nitrogen can be removed after protection of the ketone as the cyclic acetal by using sodium naphthalide in THF (Scheme 6). After protection, the diphenylphosphoramidate group can also

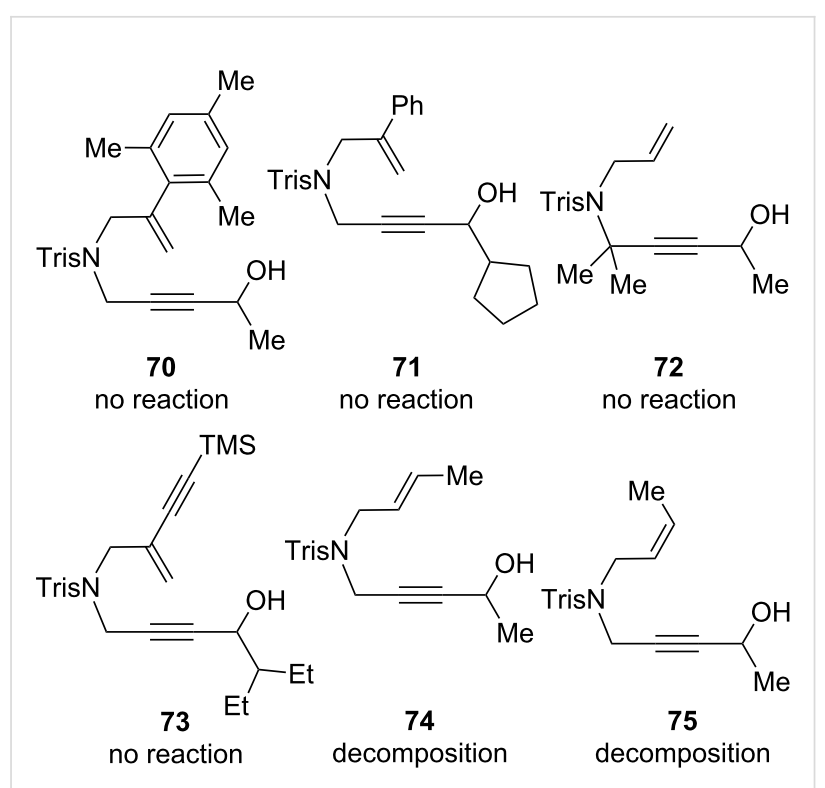

Figure 3: Failed bicycloisomerization substrates. Reactions performed at $40{ }^{\circ} \mathrm{C}$ for 16 hours with $3 \mathrm{~mol} \%$ of catalyst 1 in acetone at a $0.25 \mathrm{M}$ concentration relative to substrate.

be removed with lithium aluminum hydride in excellent yield. The absolute configuration of the [3.1.0] pyrrolidines was assigned by analogy to $\mathbf{7 6}$, which was determined to be $(R, R)$ by single crystal X-ray crystallography.<smiles>CC(=O)CC12CNCC1(C)CC21CCCC1(C)CC1(C)CN[R1]CC1(C)C</smiles>

$76 \mathrm{R}=-$ Tris, $83 \%$ yield $77 \mathrm{R}=-\mathrm{Ts}, 75 \%$ yield $78 \mathrm{R}=-\mathrm{P}(\mathrm{O})(\mathrm{OPh})_{2}, 70 \%$ yield

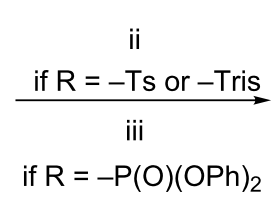<smiles>CC1(CC23CNCC2(C)C3)CCCO1</smiles>

$\mathrm{R}=-$ Tris, $91 \%$ yield $\mathrm{R}=-\mathrm{Ts}, 85 \%$ yield $\mathrm{R}=-\mathrm{P}(\mathrm{O})(\mathrm{OPh})_{2}, 78 \%$ yield

i) $\mathrm{TsOH} \cdot \mathrm{H}_{2} \mathrm{O},(\mathrm{MeO})_{3} \mathrm{CH},\left(\mathrm{CH}_{2} \mathrm{OH}\right)_{2}$, rt, $3 \mathrm{~h}$ ii) sodium naphthalide, $\mathrm{THF},-78^{\circ} \mathrm{C}$ to rt, $5 \mathrm{~min}$ iii) $\mathrm{LiAlH}_{4}, \mathrm{Et}_{2} \mathrm{O}, \mathrm{rt}, 17 \mathrm{~h}$ 


\section{Mechanistic studies}

After having successfully developed this synthetic methodology, a few questions still remained pertaining to the mechanism of the reaction. First, does the propargylic stereocenter on the enyne substrate have a significant impact on the enantioselectivity of the reaction, despite it being destroyed during redox isomerization? Second, what role does the nature of the solvent play in determining enantioselectivity? To answer these questions, we synthesized a 1,6-enyne containing an enantioenriched propargyl alcohol using our group's zinc ProPhenol chemistry (Scheme 7). By employing the opposite enantiomers of the ProPhenol catalyst, either enantiomer of propargyl alcohol can be accessed with this methodology. Additionally, no other attempted synthetic strategy was able to provide $(R)-\mathbf{5 2}$, including Noyori and CBS reduction, which highlights the utility of this asymmetric transformation.

In acetone, the nature of this stereocenter had very little impact on the enantiomeric ratio of the final product, as both $(R)$ - and $(S)-52$ gave results that were almost identical to the racemic substrate (Table 8). Interestingly, however, switching to THF provided drastically different results. While redox bicycloisomerization of $(R)-\mathbf{5 2}$ was very enantioselective, affording $\mathbf{5 3}$ in a 92.0 to 8.0 enantiomeric ratio, $(S)-52$ performed much worse. Product 53 was isolated in a 68.0 to 32.0 enantiomeric ratio in this case. The same matched/mismatched effect was observed for chiral 1,7-enynes in THF [44]. Based on these results, it is clear that the high enantioselectivity of the redox bicycloisomerization reaction of 1,6-enynes is due to acetone's ability to override any impact the propargylic stereocenter has on the course of the reaction.

Considering the data presented in Table 8, we now propose a working mechanism for the origin of enantioselectivity in the redox bicycloisomerization reaction. There are two important factors to consider when putting together such a mechanism: coordination of the propargyl alcohol on the metal center and facial selectivity for the $[2+2]$ cycloaddition. We will look at each in turn. First, coordination by the propargyl alcohol creates four possible diastereomeric, chiral-at-ruthenium intermediates (Figure 4). As long as the metal does not epimerize over the course of the reaction, this transfer of stereochemical informa-

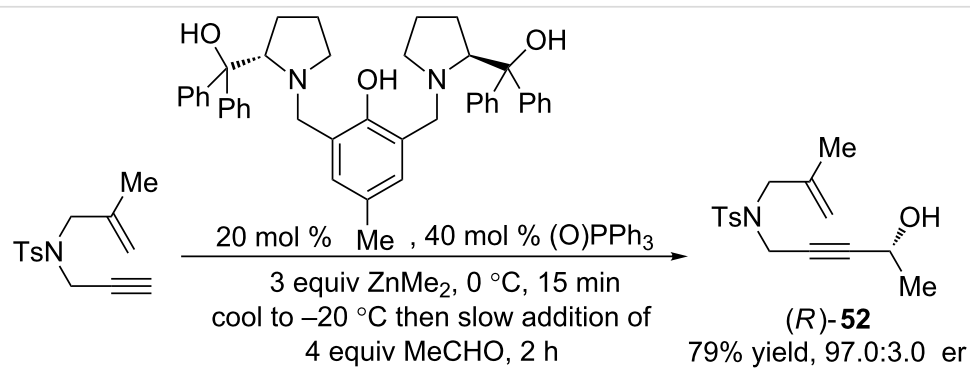

Scheme 7: ProPhenol-catalyzed addition of zinc acetylide to acetaldehyde for the synthesis of a chiral 1,6-enyne substrate.

Table 8: Effect of propargylic stereocenter on enantioselectivity.

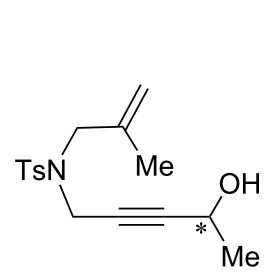

52

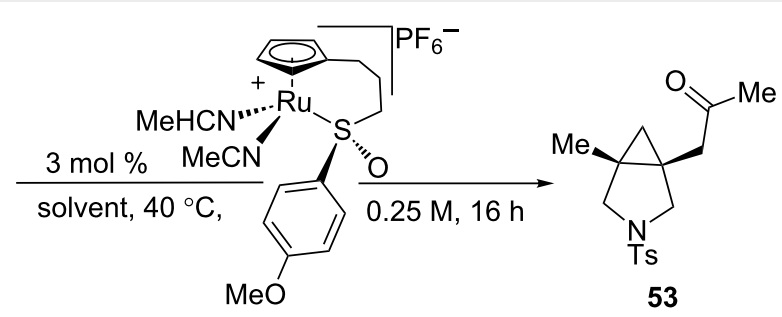

53

\begin{tabular}{|c|c|c|c|c|}
\hline entry & solvent & alcohol configuration & yield (\%) & er \\
\hline 1 & acetone & rac & 81 & $94.0: 6.0$ \\
\hline 2 & acetone & $(R)^{a}$ & 84 & $93.5: 6.5$ \\
\hline 3 & acetone & $(S)^{a}$ & 81 & $96.5: 3.5$ \\
\hline 4 & THF & rac & 52 & $80.0: 20.0$ \\
\hline 5 & THF & $(R)^{a}$ & 61 & $92.0: 8.0$ \\
\hline 6 & THF & $(S)^{a}$ & 52 & $68.0: 32.0$ \\
\hline
\end{tabular}

astarting alcohol has a 97.0:3.0 er. 


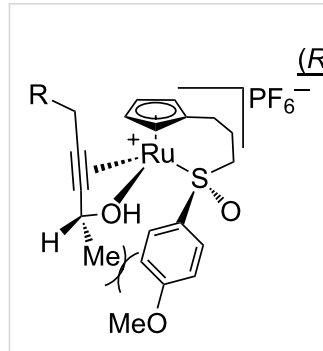

syn (disfavored)

\section{(R)-propargyl alcohol}

vS

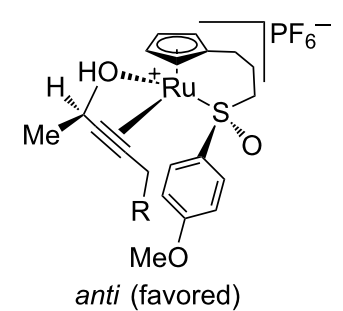

\section{(S)-propargyl alcohol}

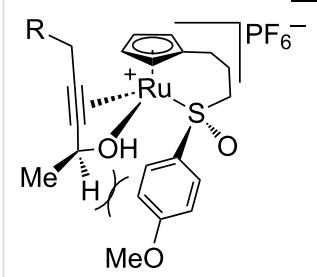

syn (disfavored) vs

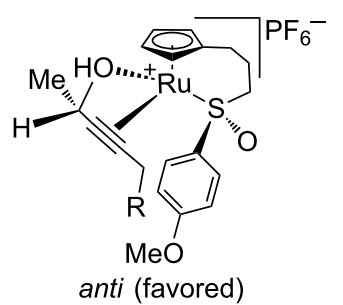

Figure 4: Diastereomeric metal complexes formed after alcohol coordination.

tion can then be transferred back to the substrate following redox isomerization, influencing the overall enantioselectivity of the process. For both the $(R)$ - and the $(S)$-propargyl alcohols, the $\mathrm{CpRu}$-sulfoxide catalyst prefers to place the stereocenter away from the steric bulk of the sulfoxide (anti configuration). Both syn configurations are disfavored, but the syn- $(R)$-configuration is energetically more taxing than the $s y n-(S)$-configuration, creating a larger energy difference between $\operatorname{syn}-(R)$ and anti- $(R)$. This larger energy difference is reflected in the higher enantioselectivities obtained for the $(R)$ enantiomer in THF (Table 8, entry 5). The smaller energetic difference between syn- $(S)$ and anti- $(S)$ means that there is less of a preference for either coordination mode, which leads to poorer enantioselectivities in THF (Table 8, entry 6).

We propose that acetone, being more Lewis basic than THF, has the effect of epimerizing the chiral-at-ruthenium intermediates formed prior to $[2+2]$ cycloaddition. The rate of epimerization is much faster than the $[2+2]$ cycloaddition, creating a classic Curtin-Hammitt scenario wherein all of the substrate is funneled into the observed enantiomer of product (Scheme 8). Rate $k_{1}$ is much slower than $k_{2}$ due to the severe steric hindrance imposed by the ligated chiral sulfoxide, which block alkene coordination. The pendant olefin prefers to approach the carbene anti to the aforementioned sulfoxide, resulting in the observed enantiomer of 53. In THF, the rate of epimerization is significantly slower than the $[2+2]$ cycloaddition, which means that the enantiomeric ratios observed in the products are affected more by the initial coordination of the propargyl alcohol.

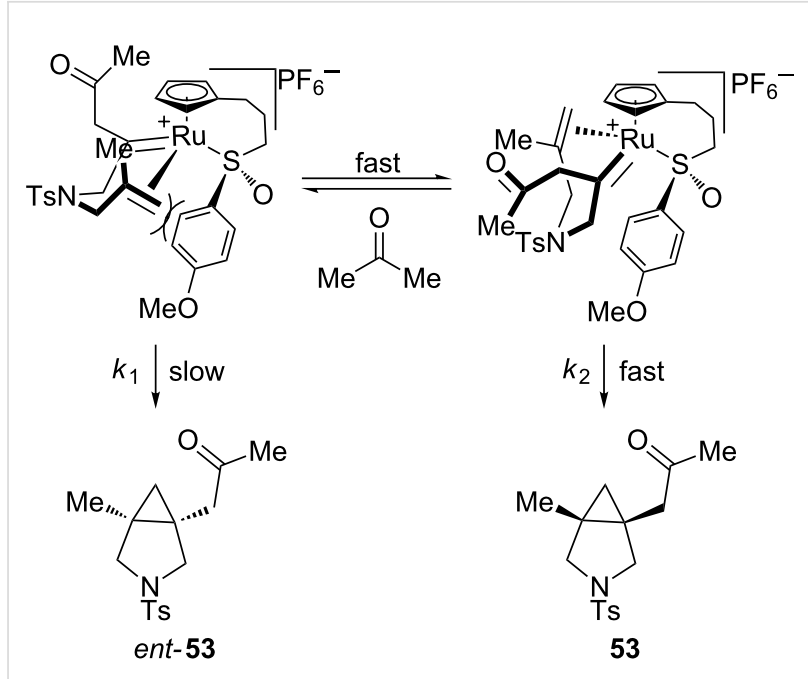

Scheme 8: Curtin-Hammitt scenario of redox bicycloisomerization in acetone.

\section{Conclusion}

In conclusion, we have developed a ruthenium-catalyzed asymmetric redox bicycloisomerization utilizing a chiral $\mathrm{CpRu}-$ sulfoxide complex 1 . This constitutes the first example of an asymmetric ruthenium-catalyzed redox isomerization known to date. We were able to demonstrate that the nitrogen protecting group on the 1,7-enynes had a significant impact on the enantioselectivity of the redox bicycloisomerization as did the choice of solvent. Extending the chemistry to the 1,6-enynes, we showed that these substrates were much more amenable to a wider range of groups on nitrogen, though a significant solvent effect was still observed in these cases. The mechanism of the reaction was then probed by performing the redox isomerization reaction on enantioenriched propargyl alcohols. While a significant matched/mismatched effect was observed in THF, no such effect was seen in acetone. We postulate that there are two different enantiodetermining steps that center around a chosen solvent's ability to epimerize a metal center following redox isomerization.

\section{Supporting Information}

\section{Supporting Information File 1}

Experimental details and NMR data of new catalysts. [http://www.beilstein-journals.org/bjoc/content/ supplementary/1860-5397-12-110-S1.pdf]

\section{Supporting Information File 2}

$\mathrm{X}$-ray crystallography data for $\mathbf{7 6}$.

[http://www.beilstein-journals.org/bjoc/content/ supplementary/1860-5397-12-110-S2.cif] 


\section{Acknowledgements}

We would like to thank the NSF for their generous support (NSF-CHE-1360634).

\section{References}

1. Nicolaou, K. C.; Vourloumis, D.; Winssinger, N.; Baran, P. S. Angew. Chem., Int. Ed. 2000, 39, 44. doi:10.1002/(SICI)1521-3773(20000103)39:1<44::AID-ANIE44>3.0.CO ;2-L

2. Babine, R. E.; Bender, S. L. Chem. Rev. 1997, 97, 1359. doi:10.1021/cr960370z

3. Laurent, B. A.; Grayson, S. M. Chem. Soc. Rev. 2009, 38, 2202. doi:10.1039/b809916m

4. Michelet, V.; Toullec, P. Y.; Genêt, J.-P. Angew. Chem., Int. Ed. 2008, 47, 4268. doi:10.1002/anie.200701589 See for a review on enyne cycloisomerizations.

5. Trost, B. M. Science 1991, 254, 1471. doi:10.1126/science.1962206

6. Wender, P. A.; Verma, V. A.; Paxton, T. J.; Pillow, T. H. Acc. Chem. Res. 2008, 41, 40. doi:10.1021/ar700155p

7. Burns, N. Z.; Baran, P. S.; Hoffmann, R. W. Angew. Chem., Int. Ed. 2009, 48, 2854. doi:10.1002/anie.200806086

8. Trost, B. M.; Lautens, M. J. Am. Chem. Soc. 1985, 107, 1781. doi:10.1021/ja00292a065

9. Oppolzer, W.; Snieckus, V. Angew. Chem., Int. Ed. Engl. 1978, 17, 476. doi:10.1002/anie. 197804761

See for a review on thermal ene reactions.

10. Trost, B. M.; Toste, F. D. J. Am. Chem. Soc. 2000, 122, 714. doi:10.1021/ja993401r

11. Fairlamb, I. J. S. Angew. Chem., Int. Ed. 2004, 43, 1048. doi:10.1002/anie.200301699

12. Watson, I. D. G.; Toste, F. D. Chem. Sci. 2012, 3, 2899. doi:10.1039/c2sc20542d

13. Chao, C.-M.; Vitale, M. R.; Toullec, P. Y.; Genêt, J.-P.; Michelet, V. Chem. - Eur. J. 2009, 15, 1319. doi:10.1002/chem.200802341

14. Watson, I. D. G.; Ritter, S.; Toste, F. D. J. Am. Chem. Soc. 2009, 131, 2056. doi:10.1021/ja8085005

15. Martínez, A.; García-García, P.; Fernández-Rodríguez, M. A.; Rodríguez, F.; Sanz, R. Angew. Chem., Int. Ed. 2010, 49, 4633. doi:10.1002/anie.201001089

16. Brissy, D.; Skander, M.; Jullien, H.; Retailleau, P.; Marinetti, A. Org. Lett. 2009, 11, 2137. doi:10.1021/ol900724z

17. Jullien, H.; Brissy, D.; Sylvain, R.; Retailleau, P.; Naubron, J.-V.; Gladiali, S.; Marinetti, A. Adv. Synth. Catal. 2011, 353, 1109. doi:10.1002/adsc.201000904

18. Goeke, A.; Kuwano, R.; Ito, Y.; Sawamura, M. Angew. Chem., Int. Ed. Engl. 1996, 35, 662. doi:10.1002/anie.199606621

19.Zhang, Q.; Lu, X.; Han, X. J. Org. Chem. 2001, 66, 7676. doi:10.1021/jo0105181

20. Hatano, M.; Mikami, K. J. Am. Chem. Soc. 2003, 125, 4704. doi:10.1021/ja0292748

21. Shintani, R.; Nakatsu, H.; Takatsu, K.; Hayashi, T. Chem. - Eur. J. 2009, 15, 8692. doi:10.1002/chem.200901463

22. Nicolaou, K. C.; Li, A.; Ellery, S. P.; Edmonds, D. J. Angew. Chem., Int. Ed. 2009, 48, 6293. doi:10.1002/anie.200901992

23. Nishimura, T.; Maeda, Y.; Hayashi, T. Org. Lett. 2011, 13, 3674. doi:10.1021/ol2013236
24. Hatano, M.; Terada, M.; Mikami, K. Angew. Chem., Int. Ed. 2001, 40, 249. doi:10.1002/1521-3773(20010105)40:1<249::AID-ANIE249>3.0.CO;2$\mathrm{X}$

25. Cao, P.; Zhang, X. Angew. Chem., Int. Ed. 2000, 39, 4104. doi:10.1002/1521-3773(20001117)39:22<4104::AID-ANIE4104>3.0.CO ;2-X

26. Trost, B. M.; Toste, F. D.; Shen, H. J. Am. Chem. Soc. 2000, 122, 2379. doi:10.1021/ja993400z

27. Teller, H.; Fürstner, A. Chem. - Eur. J. 2011, 17, 7764. doi:10.1002/chem.201101346

28. Bertani, B.; Di Fabio, R.; Micheli, F.; Tedesco, G.; Terreni, S. WO 2008031772A1, 2008.

29. Micheli, F.; Cavanni, P.; Andreotti, D.; Arban, R.; Benedetti, R.; Bertani, B.; Bettati, M.; Bettelini, L.; Bonanomi, G.; Braggio, S.; Carletti, R.; Checchia, A.; Corsi, M.; Fazzolari, E.; Fontana, S.; Marchioro, C.; Merlo-Pich, E.; Negri, M.; Oliosi, B.; Ratti, E.; Read, K. D.; Roscic, M.; Sartori, I.; Spada, S.; Tedesco, G.; Tarsi, L.; Terreni, S.; Visentini, F.; Zocchi, A.; Zonzini, L.; Di Fabio, R. J. Med. Chem. 2010, 53, 4989-5001. doi:10.1021/jm100481d

30. Kündig, E. P.; Saudan, C. M.; Bernardinelli, G. Angew. Chem., Int. Ed. 1999, 38, 1219-1223. doi:10.1002/(SICI)1521-3773(19990503)38:9<1219::AID-ANIE1219>3. $0 . \mathrm{CO} ; 2-\mathrm{D}$

31. Brinkmann, Y.; Madhushaw, R. J.; Jazzar, R.; Bernardinelli, G.; Kündig, E. P. Tetrahedron 2007, 63, 8413-8419. doi:10.1016/j.tet.2007.06.033

32. Bădoiu, A.; Bernardinelli, G.; Mareda, J.; Kündig, E. P.; Viton, F. Chem. - Asian J. 2008, 3, 1298-1311. doi:10.1002/asia.200800063 33. Maas, G. Chem. Soc. Rev. 2004, 33, 183-190. doi:10.1039/b309046a 34. Nishiyama, H. Cyclopropanation with Ruthenium Catalysts. In Ruthenium Catalysts and Fine Chemistry; Bruneau, C.; Dixneuf, P. H., Eds.; Topics in Organometallic Chemistry, Vol. 11; Springer: Berlin, Germany, 2004; pp 81-92. And references therein.

35. Matsushima, Y.; Onitsuka, K.; Kondo, T.; Mitsudo, T.-a.; Takahashi, S. J. Am. Chem. Soc. 2001, 123, 10405-10406. doi:10.1021/ja016334।

36. Onitsuka, K.; Matsushima, Y.; Takahashi, S. Organometallics 2005, 24, 6472-6474. doi:10.1021/om050739n

37. Onitsuka, K.; Okuda, H.; Sasai, H. Angew. Chem., Int. Ed. 2008, 47, 1454-1457. doi:10.1002/anie.200704457

38. Kanbayashi, N.; Onitsuka, K. J. Am. Chem. Soc. 2010, 132, 1206-1207. doi:10.1021/ja908456b

39. Kanbayashi, N.; Onitsuka, K. Angew. Chem., Int. Ed. 2011, 50, 5197-5199. doi:10.1002/anie.201101078

40. Kanbayashi, N.; Takenaka, K.; Okamura, T.-a.; Onitsuka, K. Angew. Chem., Int. Ed. 2013, 52, 4897-4901. doi:10.1002/anie.201300485

41. Trost, B. M.; Breder, A.; O’Keefe, B. M.; Rao, M.; Franz, A. W. J. Am. Chem. Soc. 2011, 133, 4766. doi:10.1021/ja200971v

42. Trost, B. M.; Rao, M.; Dieskau, A. P. J. Am. Chem. Soc. 2013, 135, 18697. doi:10.1021/ja411310w

43. Trost, B. M.; Ryan, M. C.; Rao, M.; Markovic, T. Z. J. Am. Chem. Soc. 2014, 136, 17422. doi:10.1021/ja510968h See for a leading communication on the study presented herein.

44. Rao, M. Development Of Optically Active Cyclopentadienyl Ruthenium Complexes and Their Application in Asymmetric Catalysis. Ph.D. Thesis, Stanford University, Stanford, CA, U.S.A., 2013. 
45. Watanabe, Y.; Mase, N.; Tateyama, M.-a.; Toru, T.

Tetrahedron: Asymmetry 1999, 10, 737.

doi:10.1016/S0957-4166(99)00066-X

46. Andersen, K. K. Tetrahedron Lett. 1962, 3, 93.

doi:10.1016/S0040-4039(00)71106-3

47. Andersen, K. K.; Gaffield, W.; Papanikolaou, N. E.; Foley, J. W.;

Perkins, R. I. J. Am. Chem. Soc. 1964, 86, 5637.

doi:10.1021/ja01078a047

48. Han, Z.; Krishnamurthy, D.; Grover, P.; Fang, Q. K.; Su, X.;

Wilkinson, H. S.; Lu, Z.-H.; Magiera, D.; Senanayake, C. H.

Tetrahedron 2005, 61, 6386. doi:10.1016/j.tet.2005.03.122

49. Soderquist, J. A.; Huertas, R.; Leon-Colon, G. Tetrahedron Lett. 2000,

41, 4251-4255. doi:10.1016/S0040-4039(00)00605-5

\section{License and Terms}

This is an Open Access article under the terms of the Creative Commons Attribution License

(http://creativecommons.org/licenses/by/2.0), which permits unrestricted use, distribution, and reproduction in any medium, provided the original work is properly cited.

The license is subject to the Beilstein Journal of Organic Chemistry terms and conditions:

(http://www.beilstein-journals.org/bjoc)

The definitive version of this article is the electronic one which can be found at: doi:10.3762/bjoc. 12.110 